\title{
ANALYSE DES CONDITIONS DE LA FÉCONDATION IN VITRO DE L'CEUF DE LA LAPINE
}

\author{
C. THIBAULT et L. DAUZIER \\ a vec la collaboration technique de Michelin= Gérard et Éliane Goussopoulos. \\ Station de Recherches de Physiologie animale, \\ Centre national de Recherches zootechniques, Jouy-en-Josas (S.-et-O.) \\ et Laboratoire de Zootechnie, Centre de Recherches agronomiques du Midi, \\ École nationale d'Agriculture, Montpellier (Hérault).
}

\section{SOMMAIRE}

Ce n'est qu'en 195I après la découverte par Chang et AUstin de la nécessité d'une maturation des spermatozoïdes dans les voies génitales femelles que l'attention fut attirée sur les conditions particulières que nécessite la fécondation chez les Mammifères.

On s'aperçut rapidement que même en utilisant du sperme ainsi maturé, il était impossible d'obtenir régulièrement la fécondation in vitro. D'autres conditions devaient donc se trouver remplies.

Au cours d'un travail réalisé avec 1954 lapines et 7605 ovocytes, étudiés en coupes sériées, nous avons pu, grâce à des expériences effectuées in vitro, découvrir les relations existant entre le spermatozoïde, l'ovocyte et le milieu tubaire pour que se réalise la fécondation.

L'ovocyte vierge émet une substance spermo-répulsive assimilable à une "fertilisine 》 qui interdit au spernatozoide maturé l'approche de l'ovocyte.

Pour obtenir à coup sûr la fécondation in vitro il faut provoquer la déconcentration de la " fertilisine " au voisinage même de la membrane pellucide et sa libération dans le milieu. Cette opération nécessite environ deux heures, et la pénétration des spermatozoïdes commence aussitôt après. Sur 532 ovocytes ainsi traités, 353 ont été fécondés soit $66 \mathrm{p}$. 1oo, et 418 , fécondés ou pénétrés (ayant au moins un spermatozoïde sous la membrane pellucide) soit $78,5 \mathrm{p}$. Ioo, les œufs étant fixés 4 à 7 heures après la mise en contact avec les spermatozoïdes.

Les spermatozoïdes fraîchement éjaculés (non maturés) sont insensibles à l'action de la " fertilisine " ovocytaire : ils peuvent se coller à l'ovocyte mais inversement ils ne peuvent traverser sa membrane pellucide.

L'existence d'une substance produite dans les voies génitales femelles capable de neutraliser la " fertilisine " ovocytaire a été mise également en évidence, elle permettrait, in vivo, l'élimination continuelle de la "fertilisine " ovocytaire laissant ainsi le libre accès de l'ovocyte au spermatozoïde.

L'action de cette substance ne se manifeste pas en l'absence d'oxygène.

Le spermatozoïde émet également une lysine qui cytolyse l'ovocyte vierge non lavé cultivé dans une suspension de spermatozoïdes maturés.

L'analogie avec les faits connus dans les relations entre les gamêtes chez les Invertébrés est évidente.

Ces mécanismes n'ont pu être retrouvés avec les œufs de Brębis et de Truie.

\section{INTRODUC'TION E'T BIBLIOGRAPHIE}

Les conditions dans lesquelles s'effectue la fécondation chez les Mammifères sont telles qu'il est vain d'espérer en découvrir les mécanismes par l'étude in vivo.

C'est pourquoi depuis I 953 nous avons cherché à connaître les conditions néces- 


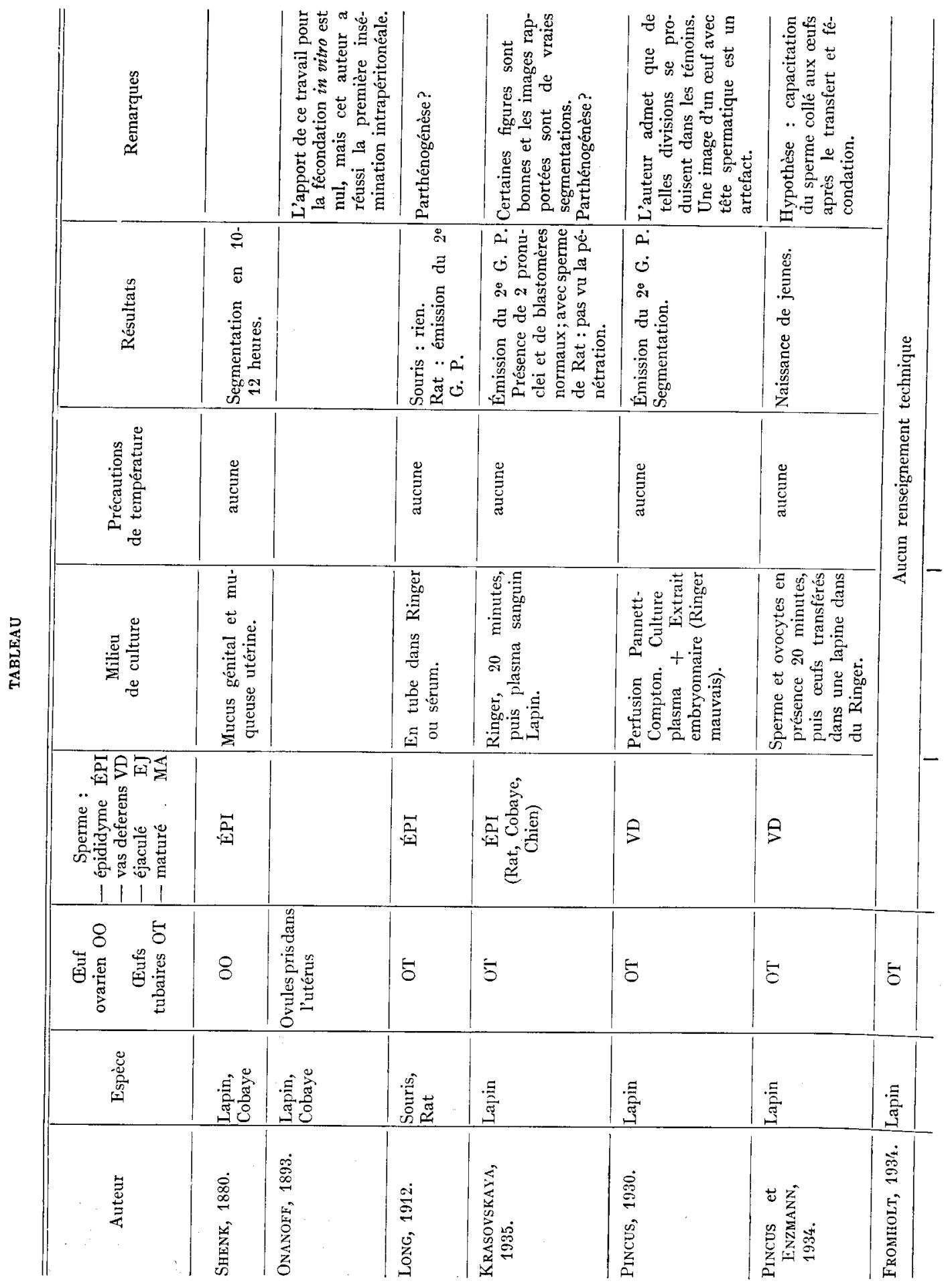


FÉCONDATION in vitro DE L'GUF DE LAPINE

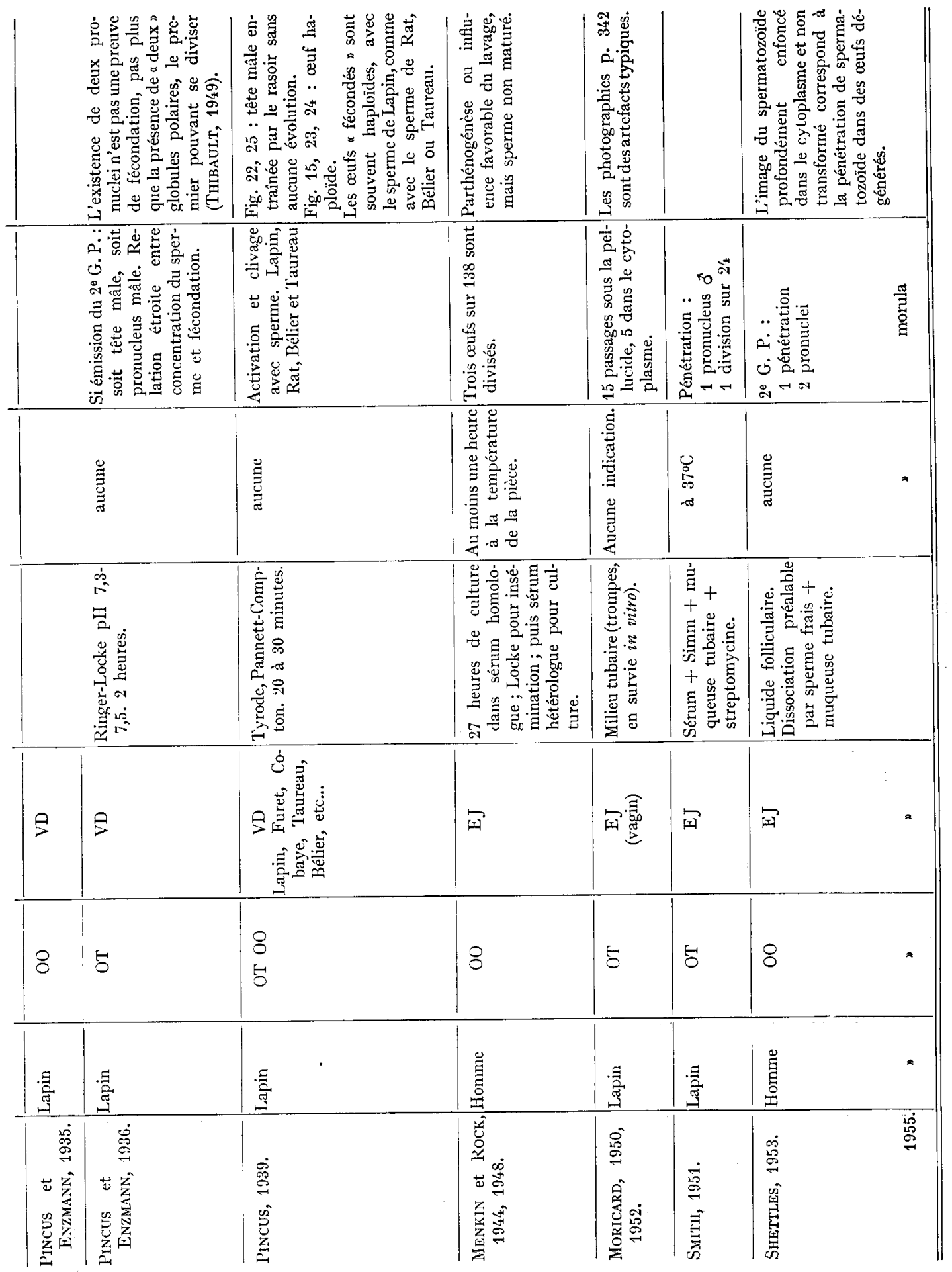


280

C. THIBAULT ET L. DAUZIER

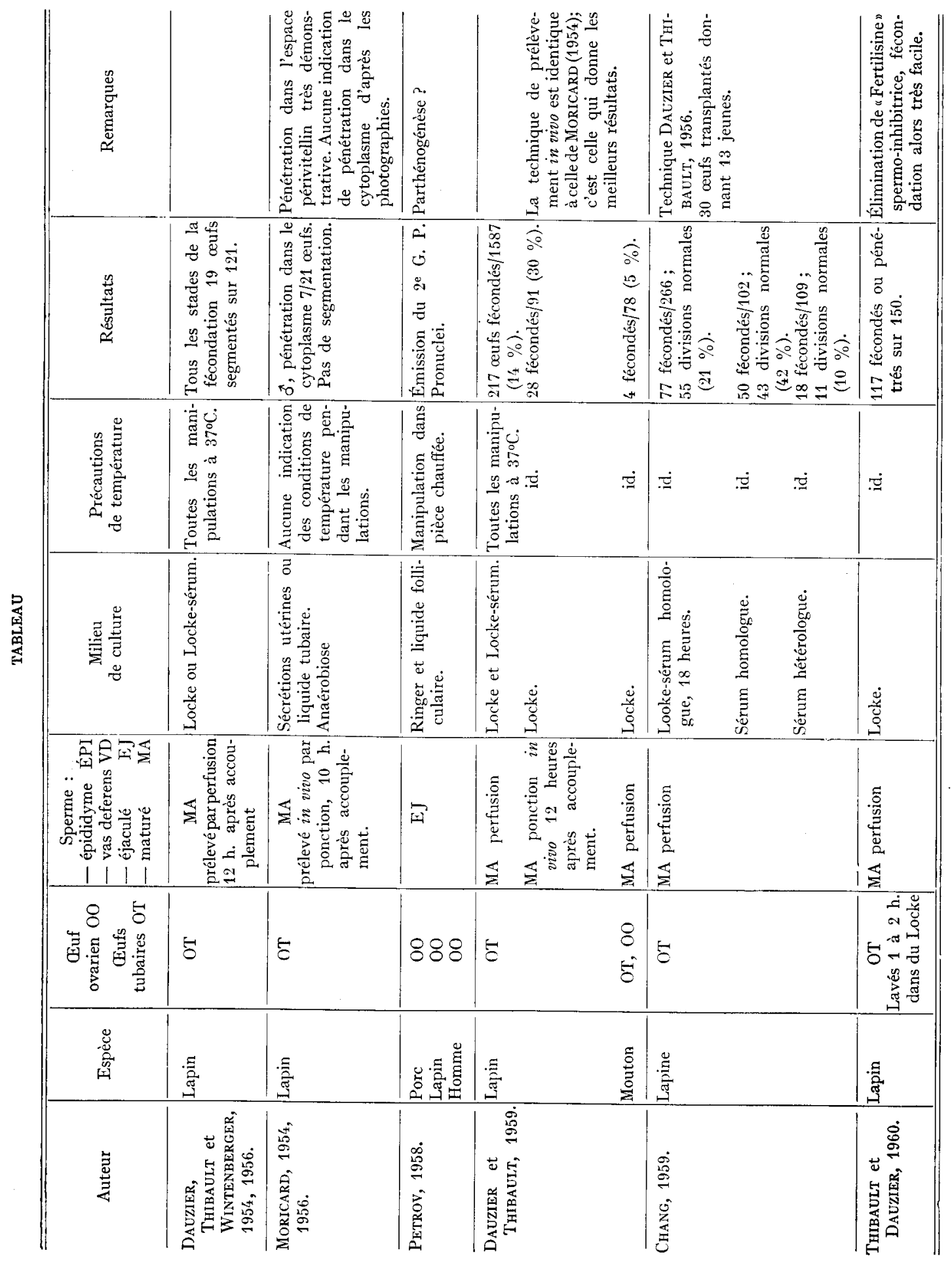


saires pour obtenir la fécondation aussi régulièrement in vitro qu'elle se produit in vivo. Après des succès partiels nous sommes arrivés récemment à mettre en évidence la condition fondamentale pour que la fécondation se produise régulièrement.

C'est pourquoi nous publions maintenant nos résultats car nous pensons que cette technique apportera des possibilités expérimentales beaucoup plus grandes aux nombreux chercheurs qui utilisent l'œuf des Mammifères, pour des études sur la polyspermie, la polyploïdie, la fécondation hétérospermique, l'hybridation, etc.

La littérature scientifique fait état de fécondations réussies in vitro et le lecteur non averti pourrait croire la question résolue. Nous avons donc groupé par ordre chronologique, sur les tableaux ci-contre, tous les résultats publiés en mettant spécialement en évidence les techniques employées.

Il apparaît tout d'abord que malgré les travaux de PrNcus et SHapro (I940) et de Thibauli (I947-I949) sur l'activation parthénogénétique par le refroidissement de l'ovocyte de Mammifère, seuls, Smith (I95I), nous-mêmes et PETrov (I958) spécifient avoir évité le refroidissement des ovocytes pendant les manipulations. On peut penser qu'il en fut de même dans les expériences de Moricard, compte tenu de la technique utilisée pour le prélèvement des ovocytes.

Aussi les émissions de $2^{\mathrm{e}}$ globule polaire ou les segmentations observées après insémination avec du sperme fraîchement éjaculé ou avec du sperme épididymaire peuvent s'expliquer par une activation parthénogénétique.

Il peut en être de même de certains cufs à deux pronucléi puisque 1'un de nous a montré que des œufs parthénogénétiques de Lapine pouvaient posséder deux pronucléi ('ThibauLT, I949).

Depuis r95I, on sait également que les spermatozoïdes de Rat et de Lapin n'acquièrent leur pouvoir fécondant qu'après un séjour de 4 à Io heures dans les voies génitales femelles (CHANG, AUSTIN). Nous avons montré que cette maturation était également nécessaire chez la Brebis (Dauzier et ThIbaulT, I959) et qu'elle est probable chez la Truie (ThrbauLT, I959). On peut donc penser qu'il s'agit d'un phénomène général propre aux Mammifères.

Il ne reste donc, comme fécondations certaines, que celles rapportées par MORICARD, I954-I955, et par nous-mêmes, puisque ce sont les seules expériences où à la fois furent utilisés du sperme prélevé dans les voies génitales de la femelle, et des ovocytes préservés du refroidissement.

Le film réalisé par MORICARD (I954-I955) montre clairement le spermatozoïde fécondant ayant franchi la membrane pellucide et nageant dans l'espace périvitellin, mais ne met pas en évidence la pénétration dans le cytoplasme, seul critère absolu de la fécondation.

MORICARD n'a pas obtenu de segmentation et les photographies de coupe d'ovocytes qu'il rapporte, même en $\mathbf{1} 955$, ne permettent pas d'interpréter les spermatozoïdes présents comme ayant pénétré dans le cytoplasme ; par contre 1'un des oufs montre deux pronucléi indiscutables.

Nous avons rapporté en I954 ( $a$ et b) ,I956, I959, I960, nos principaux résultats décrivant tous les stades de la pénétration du spermatozoïde, de la formation des pronucléi et de la segmentation. Austin les a sévèrement critiqués n'ayant pas réussi à répéter lui-même nos expériences. Il vient d'y parvenir (communication personnelle, I96I). Chang en suivant notre technique est parvenu en I959 à un pourcentage de succès comparable à ceux que nous avons rapportés de I954. à I959. Il a obtenu de 
jeunes Lapins à partir d'ovocytes fécondés in vitro et transplantés dans une mère réceptrice.

Nous avons nous-mêmes obtenu des jeunes à partir d'œufs regreffés dans une Lapine hôte (fig. I.).

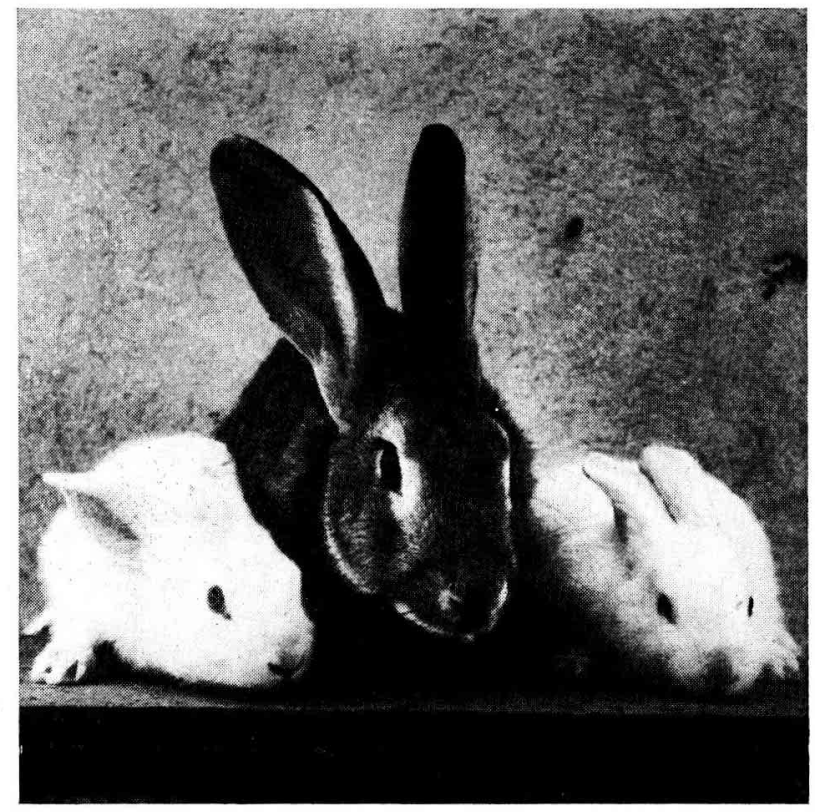

FIG. I. - Jeunes lapins provenant d'ovocytes fécondés in vitro, cullivés 24 heures, puis greffés dans une pemelle-hôte.

Plus récemment ( $I$ G60) nous avons pu montrer que la fécondation pouvait être obtenue presque aussi régulièrement in vitro qu'in vivo à condition d'éliminer par un lavage prolongé une substance qui, émise par l'ovocyte de lapine, empêche le spermatozoïde d'approcher.

\section{MATÉRIEL, E'T MÉTHODES}

L'ensemble de nos expériences a porté sur 7605 ovocytes et I954 lapines provenant d'élevages non sélectionnés sur 97 ovocytes de Brebis et sur 87 ovocytes de Truie.

\section{$\mathrm{I}^{\circ}$ Mode de prélèvement des spermatozoïdes :}

Les spermatozoïdes mûrs ( $\left.{ }^{1}\right)$ ont toujours été obtenus par collecte au vagin artificiel (Bélier, Lapin et Verrat).

Les spermatozoïdes " maturés ( ont été recueillis soit in vivo, soit après abattage, le plus souvent I 2 heures après accouplement (Lapine Normale : L. N.).

Pour les obtenir après abattage, chez la Lapine, deux méthodes ont été utlisées :

(1) Nous appellerons spermatozoïdes maturés (" capacités" CHANG. 1951) ceux qui ont subi leur maturation dans les voies génitales femelles par opposition aux spermatozoides fraîchement éjaculés que nous qualifierons de mûrs réservant le qualificatif d'immaiures à ceux qui cheminent du testicule vers le canal déférent. 
a) Perfusion par $0,2 \mathrm{ml}$ de Locke à $37,5^{\circ} \mathrm{C}$ de chacune des cornes, de la manière suivante : le liquide est introduit par la jonction isthme-corne, le bas de la corne utérine étańt maintenu fermé. On laisse quelques instants le liquide dans la corne et on l'expulse en faisant glisser la corne entre les doigts depuis l'extrémité tubaire jusqu'à l'extrémité vaginale; le liquide mélangé au fluide utérin est recueilli dans un verre de montre, maintenu à $37^{\circ} \mathrm{C}$ à l'abri de la dessiccation. La présence de spermatozoïdes fléchants est contrôlée et une estimation subjective globale de leur nombre et de leur motilité est chiffrée par un même observateur de ò̀ 5 .

b) Dans certains cas, où des sécrétions utérines remplissaient abondamment les cornes nous nous sommes contentés de recueillir ces sécrétions. Le même contrôle fut exercé pour reconnaître la présence de spermatozoïdes et leurs caractéristiques.

Chez la Brebis et la Truie seule la première méthode a été utilisée.

Les spermatozoïdes présents dans les cornes utérines sont généralement agglutinés, soit entre eux, soit plus généralement autour de débris cellulaires. Nous nous sommes aperçus qu'une désagglutination spontanée se produisait dans les cornes laissées sans précautions spéciales, à la température ambiante (I 5 à $20^{\circ} \mathrm{C}$ ) pendant une heure, ou plus rapidement à plus basse température. Cherchant à utiliser ces spermatozoïdes, nous les avons recueillis par perfusion comme il est indiqué précédemment.

Tous les auteurs, à l'exception de Moricard, ont utilisé soit le sperme fraîchement éjaculé, soit le sperme épididymaire suspendu dans un liquide physiologique. MORICARD dans une première série d'expérience (I950-1952) récupère le sperme dans le vagin de la Lapine une heure après accouplement; dans ces conditions le sperme n'a pas eu le temps de subir sa maturation ( 6 à 8 heures) et le sperme vaginal est toujours envahi par de nombreux polynucléaires. C'est probablement pour ces deux raisons que dans ses publications ultérieures de I953-I955, MORICARD fait état d'une technique différente : prélèvement du sperme par pipetage "in vivo " dans la corne utérine. Comme nous le verrons, on doit considérer cette technique comme la meilleure. Aussi pour obtenir des spermatozoïdes in vivo avons-nous procédé d'une façon analogue : la Lapine est anesthésiée au nembutane et on introduit après laparotomie, une pipette en verre à travers la corne utérine dans la lumière de la partie inférieure des cornes. L'extrémité de la pipette est ensuite amenée de la partie inférieure à la partie supérieure des cornes, le liquide utérin contenant les spermatozoïdes pénétrant par capilarité dans la pipette.

\section{$2^{\circ}$ Mode de prélèvement des ovocytes vierges :}

Chez la Lapine, les ovocytes ont été recherchés I 2 heures après accouplement avec un mâle vasectomisé, chez la Truie 36 à 40 heures après le début des chaleurs et chez la Brebis, 26.27 heures après le début des chaleurs, une injection intraveineuse d'hormone gonadotrope pratiquée en début d'œestrus permettant d'obtenir l'ovulation $24 \pm \mathrm{I}$ heure plus tard (Ortavant, Thibault, Wintemberger, I949).

Ils ont été recueillis par perfusion des trompes avec du Locke, après abattage de la femelle. Ils étaient aussitôt soit replacés dans les tubes de culture, soit mis à laver pendant un temps variable, dans les conditions suivantes.

a) Lavage par rotation discontinue.

Les ovocytes, lorsqu'ils étaient lavés, étaient placés dans des tubes de verre de $7 \mathrm{~cm}$ de long et de 3 ou $5 \mathrm{~mm}$ de diamètre intérieur (" petits tubes" ou "gros tubes ") contenant soit o,3 ml de Locke (petits tubes), soit $0,6 \mathrm{ml}$ (gros tubes).

La colonne de Locke est amenée au centre du tube et une goutte d'huile de paraffine introduite à chaque extrémité isole le liquide de culture par deux colonnes d'air (fig. II), ces tubes étaient introduits dans les logements d'une couronne de $8 \mathrm{~cm}$ de diamètre. Cette couronne était mue par un moteur asservi par un " chronotron" qui toutes les 20 à 60 secondes (selon les expériences) faisait effectuer à la couronne I tour et demi, le démarrage étant assez brusque. De cette manière les ovocytes qui déposent à la partie inférieure du tube pendant l'arrêt, étaient décolés par le démarrage et traversaient le tube diamétralement sous l'effet de la pesanteur, quand, après un tour et demi, la couronne s'arrêtait à la position diamétralement opposée (fig. 12).

b) Lavage par lévigation manuelle dans un verre de montre.

Les ovocytes placés dans un verre de montre étaient agités régulièrement toutes les ${ }_{5} 5$ minutes,

La durée de ces différents lavages a varié de 25 à 157 minutes, le milieu étant généralement renouvelé une ou deux fois.

Toutes les opérations ont été effectuées à $37,5^{\circ} \mathrm{C}$.

\section{$3^{\circ}$ Techniques de culture :}

La plupart des expériences ont été réalisées de la manière suivante : les ovocytes étaient placés dans un tube de verre de $7 \mathrm{~cm}$ de long, de $3 \mathrm{~mm}$ de diamètre intérieur et contenant environ $0,3 \mathrm{ml}$ de Locke ; immédiatement après les spermatozoïdes recueillis dans le tractus femelle étaient intro- 
duits au voisinage des œufs par une micropipette. Puis le tube était fermé à ses deux extrémités comme il a été décrit précédemment. Ces opérations étaient effectuées sous un stéréo-microscope. bes $)$.

Nous avons également utilisé des tubes de culture de diamètre inférieur à I, 5 mm («microtu-

Nous avons utilisé le Locke à un ph voisin de 7,0 comme milieu pour les fécondations car des expériences préalables ne nous ont pas permis d'observer de différence en faveur du sérum ou du mélange Locke-sérum, dans une gamme de $\mathrm{pH}$ étendue.

Pendant I à 4 heures, les tubes étaient placés soit sur des supports fixes, soit dans des portetubes rotatifs, à $37,5^{\circ} \mathrm{C}$.

Après cette période de mise en présence avec les spermatozoïdes, les œufs étaient soit transportés dans un nouveau milieu de culture (Locke, Locke-sérum, sérum), pour suivre leur développement, soit fixés immédiatement pour études histologiques.

Dans certaines expériences nous avons utilisé des trompes contenant soit des spermatozoïdes (Lapine accouplée avec un mâle fécond 8 à 9 heures auparavant), soit des ovocytes (Lapine accouplée avec un mâle vasectomisé I 2 à I 3 heures avant). Ces trompes étaient mises en survie pour I à 4 heures dans du Locke oxygéné on non, après avoir reçu soit des ovocytes, soit des spermatozoïdes recueillis dans les conditions indiquées précédemment, de façon à essayer d'obtenir la fécondation dans des trompes ainsi mises en survie.

Dans beaucoup d'expériences, nous avons utilisé les ovocytes de l'une des trompes comme témoins : nous n'avons observé qu'un seul cas possible d'activation parthénogénétique.

\section{$4^{0}$ Contrôle de la fécondation.}

C'est seulement dans un petit nombre d'expérience que nous nous sommes contentés de contrôler la réussite de la fécondation par la segmentation, soit en culture à $37,5^{\circ} \mathrm{C}$ dans du sérum homologue ou du Locke-sérum, soit par transplantation dans d'autres Lapines.

Dans la plupart de nos expériences, en effet, nous avons procédé à des fixations précoces, de $2 \mathrm{~h} 30 \grave{a} 7$ heures après l'insémination in vitro Nous avons pensé que seule une analyse précoce systématique, autorisant une identification séparée des éléments mâle et femelle, permettait de conclure à la fécondation.

Les fixations ont été effectuées soit au Bouin, soit au Helly. La double inclusion (gélose-paraffine, Thibault, 1949) était toujours pratiquée. Les coupes sériées de roue étaient colorées à l'hématoxyline de Regaud ou au Feulgen, et les œufs analysés section par section.

Chez la Lapine, lorsque le spermatozoïde pénètre dans le cytoplasme, instantanément sa tête gonfle et en quelques instants il a perdu cet aspect en feuille qui caractérise les spermatozoïdes libres. Cette image, tout à fait caractéristique ne laisse aucun doute sur la réalité de la fécondation et permet de conclure que les images de Pincus (I939, fig. 22 et 25 ) et de Moricard (I949, I95I, 1952) correspondent à des artefacts, les spermatozoïdes ayant été entraînés dans le cytoplasme au cours des manipulations (planche i fig. 2).

De plus, lorsqu'il s'agit d'une véritable pénétration, on retrouve toujours, chez la Lapine, au voisinage de la tête mâle, la pièce intermédiaire.

Nous avons longtemps pensé que l'on devait considérer la rétraction de l'œuf comme un signe probable d'activation, de même que la rotation du deuxième faisceau de maturation. Nous ne le pensons plus : beaucoup d'œufs fécondés occupent tout le volume intérieur de la membrane pellucide pendant les premières heures de la fécondation au moins, alors que les œufs non fécondés d'une même ponte sont parfois légèrement rétractés.

Les œufs que nous indiquons dans ce mémoire comme fécondés sont donc ceux qui présentent leur deuxième globule polaire à l'exclusion de trois oufs digyniques contenant un pronucleus mâle et deux pronucléi femelles (voir THIBAUL, 1962) et, soit un spermatozoïde gonflant dans le cytoplasme avec formation astérienne à l'extrémité de la pièce intermédiaire, soit deux pronucléi dont il est aisé de reconnaître le mâle du femelle (Thibault, 1962); la pièce intermédiaire pouvant ou non être visible (fig. $\mathrm{I}, 3,4,5,6$ ).

En outre, comme les techniques de fixation et de coloration employées permettent de connaitre aisément le nombre de spermatozoides présents contre, dans et sous la pellucide, nous avons dénombré Ies œufs pénétrés, c'est-à-dire ceux possédant un ou plusieurs spermatozoïdes sous la membrane pellucide mais sans qu'il y ait encore eu pénétration d'un élément mâle dans le cytoplasme ovulaire. 


\section{RÉSULTATS \\ A. - LAPINE \\ Io Culture d'ovocytes et de sperme maturé.}

a) en "petits tubes". - C'est la technique de référence que nous avons utilisée tout au long de nos expériences et qui consiste à mélanger dans un " petit tube " des ovocytes et des spermatozoïdes prélevés comme nous l'avons indiqué.

Nous avons remarqué que sil'on plaçait les ovocytes avant les spermatozoïdes dans les " petits tubes " le pourcentage de fécondation était supérieur à celui obtenu en plaçant d'abord les spermatozoïdes et en leur ajoutant les ovocytes immédiatement récoltés (DaUzier et Thibaulit, I956).

Comme moyennes de référence pour les cultures d'ovocytes et de sperme maturé, les ovocytes étant placés les premiers, nous prendrons les valeurs rapportées récemment (THIBAULT et DAUzIER, I960) à savoir :

43 pontes fécondées sur I32, soit 32,5 p. Ioo ;

I2 I œufs fécondés sur 922 , soit I3,I p. I00 ;

I62 œufs fécondés ou pénétrés, soit I7,6 p. Ioo ;

nombre moyen, par ovocyte, de spermatozoïdes sous la pellicule dans les cufs fécondés ou pénétrés : I.

b) En "microtubes». - On pouvait penser que les spermatozoïdes, subissant un effet de dilution brutal au moment de la perfusion, perdaient rapidement leur motilité et leur pouvoir fécondant.

En plaçant les ovocytes dans un très petit volume et en y introduisant également une partie du perfusat obtenu avec o,I $\mathrm{ml}$ de Locke par corne (L. N.), il devait être possible de réduire l'effet de dilution et d'augmenter la fécondité.

Le volume total dans les " microtubes " était environ le tiers du volume utilisé dans les petits tubes, soit $0,1 \mathrm{ml}$. Cependant les résultats furent nettement plus défavorables :

Sur I3 pontes, 4 furent fécondées, soit $30 \mathrm{p}$. Ioo, donnant 5 œufs fécondés et 8 oufs pénétrés sur $6 \mathrm{I}$, soit 8,2 p. Iood'ovocytes fécondés et I3,I p. Ioo d'ovocytes fécondés ou pénétrés.

L'effet toxique de la dilution ne paraissait donc pas pouvoir être retenu, cependant pour nous en assurer nous avons étudié l'influence de la durée de conservation in vitro, après perfusion, sur la fécondance des spermatozoïdes.

Le tableau suivant montre que pendant près d'une heure, il n'y a pratiquement pas de modification du pouvoir fécondant des spermatozoïdes dilués (tableau r).

TABIEAU I

Conservation des spermatozoïdes maturés, à $37,5^{\circ} \mathrm{C}$.

\begin{tabular}{|c|c|c|c|c|}
\hline Temps conservation & Nombre pontes & $\begin{array}{c}\text { Nombres de } \\
\text { pontes fécondées }\end{array}$ & $\begin{array}{l}\text { Nombre total } \\
\text { ovocytes }\end{array}$ & $\begin{array}{l}\text { Nombre ovocytes } \\
\text { fécondés }\end{array}$ \\
\hline $5-10 \mathrm{mn}$ & 68 & $27(39,7 \%)$ & 564 & $95(16,8 \%)$ \\
\hline 35 à $50 \mathrm{mn}$ & 10 & $3(33 \%)$ & 51 & $9(17,6 \%)$ \\
\hline 85 à $120 \mathrm{mn}$ & 13 & $1(7,6 \%)$ & 81 & $1(1,2 \%)$ \\
\hline
\end{tabular}


Comme dans toutes nos expériences, effectuées en plaçant les spermatozoïdes d'abord et les ovocytes ensuite, les spermatozoïdes n'ont pas séjourné plus de I5 minutes avant que les ovocytes soient introduits à leur voisinage, nous avons conclu que la différence observée selon que les ovocytes étaient placés avant ou après les spermatozoïdes ne pouvait s'expliquer par une diminution de la fécondance de ces derniers.

\section{$2^{\circ}$ Influence de l'agglutination des spermatozoïdes.}

Nous avons réalisé des fécondations en utilisant des spermatozoïdes désagglutinés après un séjour de une heure dans les cornes à la température ambiante.

Ces résultats ont été particulièrement mauvais puisque 4 ovocytes seulement furent fécondés sur un total de 46 ovocytes $(8,6$ p. I00). Ces œufs provenant de 2 pontes sur 7 pontes utilisées.

La contre-épreuve consistant à inséminer par le pavillon in vivo des lapins venant d'ovuler avec des perfusats contenant des spermatozoïdes désagglutinés devait montrer que ce sperme reste fécondant :

Igovocytes furent fécondés sur 34 (56 p. Ioo) provenant de 6 des 7 Lapines utilisées.

Notons cependant que le taux de fécondité est plus faible que celui obtenu avec le perfusat recueilli dès l'abattage $(89 \mathrm{p}$. Ioo).

\section{$3^{\circ}$ Influence du nombre de spermatozoïdes.}

Nous avons essayé de voir s'il existait une relation entre la fréquence des fécondations et la qualité du sperme recueilli par perfusion, qualité estimée globalement par une note de o à 5 , par un même observateur.

Si l'on divise les perfusats en deux catégories : les perfusats contenant peu ou très peu ( $\mathrm{I}, 2$ et 3 ) et ceux contenant beaucoup de spermatozoïdes (4 et 5 ), on obtient une différence importante : $14,7 \mathrm{p}$. Ioo contre $20,0 \mathrm{p}$. Ioo.

Ces résultats sembleraient indiquer qu'il y a un rapport entre le nombre de spermatozoïdes introduits au voisinage des oufs et le taux de fécondation.

En fait, l'analyse de chacune des classes (Tableau 2) montre de grandes variations entre elles qui retirent toute signification à l'interprétation globale, c'est ainsi, par exemple, qu'avec les perfusats classés 2 on a obtenu 28 œufs fécondés sur I56 soit I8 p. Ioo alors qu'avec les perfusats classés 5 , donc ceux contenant le plus de spermatozoïdes mobiles, I4 œufs ont été fécondés sur I03 soit I3,6 p. Ioo.

TABLEAU 2

Influence de la qualité du sperme (nombre, motilité) sur la fécondation.

\begin{tabular}{|c|c|c|c|c|c|c|c|c|c|}
\hline \multicolumn{2}{|c|}{$\leqslant 1$} & \multicolumn{2}{|c|}{2} & \multicolumn{2}{|c|}{3} & \multicolumn{2}{|c|}{4} & \multicolumn{2}{|c|}{5} \\
\hline N. Eufs & Féc. & N. (Eufs & Féc. & N. (Eufs & Féc. & N. Eufs & Féc. & N. CEufs & Féc. \\
\hline 159 & $12 \%$ & 156 & $\begin{array}{c}28 \\
18 \%\end{array}$ & 211 & $\begin{array}{c}25 \\
11,8 \%\end{array}$ & 458 & $\begin{array}{c}97 \\
21,3 \%\end{array}$ & 103 & $\begin{array}{c}14 \\
13,6 \%\end{array}$ \\
\hline \multicolumn{6}{|c|}{72 œufs sur 526 , soit $13,7 \%$} & \multicolumn{4}{|c|}{111 œufs sur 561 , soit $20 \%$} \\
\hline
\end{tabular}


Cette conclusion est presque logique puisque même avec les perfusats notés les plus bas on introduit encore plus de spermatozoïdes au voisinage des œufs qu'il n'en existe dans les conditions naturelles dans les trompes.

Ainsi il semblait difficile d'imputer la faiblesse et l'inconstance des résultats aux spermatozoïdes. L'amélioration relative observée en plaçant les ovocytes avant les spermatozoïdes, et l'effet défavorable d'une réduction du volume (" micro-tubes »), ne pouvait s'expliquer en considérant uniquement le gamète mâle.

La rotation continue du tube de culture semblait accroître le pourcentage d'œufs fécondés ou pénétrés (I $\mathrm{p}$. Ioo contre I $2 \mathrm{p}$. Ioo - $26 \mathrm{p}$. IOo contre $2 \mathrm{I}$ p. IOo sur I $4 \mathrm{I}$ et Ioo ovocytes respectivement).

Nous avons alors étudié les facteurs liés à l'ovocyte lui-même.

\section{$4^{\circ}$ Action du vieillissement des ovocytes.}

On sait que dans les conditions naturelles, l'ovocyte âgé est plus facilement pénétré par le spermatozoïde, ceci se traduisant par une augmentation importante de la polyspermie.

Nous avons utilisé soit des ovocytes ayant séjourné in vivo dans la trompe 4 heures environ après l'ovulation, soit des ovocytes ayant séjourné I à 2 heures in vitro à $37,5^{\circ} \mathrm{C}$.

a) Ovocytes prélevés dans les trompes 4-5 heures après l'ovulation:

Io pontes ont été fécondées sur un total de I8 étudiées.

Le pourcentage d'ovocytes fécondés a atteint 24,5 p. Ioo (24 sur 97 ovocytes) ; celui des ovocytes fécondés et pénétrés s'est élevé à $27,7 \mathrm{p}$. Ioo.

Ce pourcentage d'œufs fécondés était le plus élevé de ceux que nous avions obtenu jusqu'ici, mais il existait encore trop de différence d'une ponte à l'autre pour que ces résultats indiquent autre chose qu'une tendance.

b) Ovocytes conservés I à 3 heures in vitro avant l'insémination:

Les ovocytes prélevés I2 heures après accouplement ont été conservés une à deux heures dans un verre de montre, puis mis en "petits tubes " et inséminés.

Les résultats suivants montrent quel'amélioration est nette, spécialement quand les ovocytes sont conservés dans le Locke (Tableau 3).

TABLEAU 3

Influence de la conservation des ovocytes in vitro avant l'insémination.

\begin{tabular}{l|c|c|c|c|c}
\hline $\begin{array}{c}\text { Séjour des } \\
\text { Ovocytes }\end{array}$ & $\begin{array}{c}\text { Nombre de } \\
\text { Lapines }\end{array}$ & $\begin{array}{c}\text { Nombre de pontes } \\
\text { fécondées ou } \\
\text { pénétrées }\end{array}$ & $\begin{array}{c}\text { Nombre total } \\
\text { d'œufs }\end{array}$ & $\begin{array}{c}\text { Nombre d'œufs } \\
\text { fécondés }\end{array}$ & $\begin{array}{c}\text { Nombre d'œufs fé- } \\
\text { condés et pénétrés }\end{array}$ \\
\hline $\begin{array}{c}\text { Locke } \\
1 \text { à } 2 \text { h.... }\end{array}$ & 12 & $9(75 \%)$ & 105 & $33(32 \%)$ & $56(53 \%)$ \\
\hline $\begin{array}{c}\text { Sérum } \\
1 \text { à } 2 \text { h, puis }\end{array}$ & 4 & $1(25 \%)$ & 39 & $9(23 \%)$ & $14(35,8 \%)$ \\
\hline
\end{tabular}


Cette amélioration des résultats après conservation des ovocytes, spécialement dans du Locke in vitro, permettait de penser à une maturation analogue à celle des spermatozoïdes, hypothèse qui avait été suggérée à Austin (I954) par l'existence d'un délai entre le moment de l'ovulation et l'apparition des premiers œufs fécondés chez le Rat et le Hamster.

L'analyse cytologique des auts fécondés ou non, nous a amenés à penser que l'ovocyte vierge diffusait une substance qui interdisait l'approche du spermatozoide maturé. En effet, autour des œufs fécondés une partie des spermatozoïdes se trouvent collés contre la pellucide, ou la traversent, tandis qu'autour des ovocytes non fécondés, les spermatozoïdes restent à une distance de quelques $\mu$ (fig. Io et 9), ou même restent très éloignés des œufs : microtubes (fig. 7 et 8 ).

\section{$5^{\circ}$ Action favorable du lavage des ovocytes.}

Cette hypothèse devait se révéler exacte. En éliminant par lavages successifs la substance présumée, nous avons réussi à obtenir régulièrement la fécondation et à permettre l'approche et la traversée de la membrane pellucide à un nombre presque aussi élevé de spermatozoïdes qu'au cours d'une fécondation normale.

Une première série d'expériences au cours desquelles les lavages furent effectués soit en verre de montre par lévigation, soit en petit tube ou en gros tube par rotation discontinue, permettaient d'obtenir 66 p. Ioo, 65 p. Ioo et 65 p. Ioo de fécondation sur $4 \mathrm{I}, 60$ et 62 ovocytes, repectivement.

L'analyse de ces premiers résultats montrait également que le nombre de spermatozoïdes présents dans et sous la membrane pellucide 8 heures après la mise en présence des gamètes se rapprochait sensiblement de ceux observés in vivo dans les mêmes délais particulièrement après lavage dans les gros tubes : I9,2 et 9 contre 6,4 et Ir,4 dans les témoins, contrairement à ce que nous observions sans lavage préalable.

Les résultats étaient donc totalement différents de ceux obtenus jusqu'alors et vérifiaient 1'hypothèse précédente.

Les expériences suivantes devaient la confirmer et la préciser.

a) Lavage pendant 24 à 157 minutes :

Dans toutes ces expériences, après le lavage des ovocytes, ovocytes et spermatozoïdes étaient placés au contact dans un tube en rotation discontinue et fixés 6 à 8 heures plus tard.

Il ressort clairement du tableau 4 :

TABLEAU 4

Influence de la durée du lavage des ovocytes sur leur fécondation.

\begin{tabular}{|c|c|c|c|c|c|c|c|c|c|}
\hline \multirow{2}{*}{$\begin{array}{l}\text { Durée } \\
\text { lavage }\end{array}$} & \multirow{2}{*}{$\begin{array}{l}\text { Nombre } \\
\text { Lapines } \\
\text { (pontes) }\end{array}$} & \multirow{2}{*}{$\begin{array}{l}\text { Nombre } \\
\text { pontes } \\
\text { fécondées }\end{array}$} & \multirow{2}{*}{$\begin{array}{c}\text { Ovocytes } \\
\text { Nombre } \\
\text { total }\end{array}$} & \multicolumn{2}{|c|}{$\begin{array}{l}\text { Ovocytes } \\
\text { fécondés }\end{array}$} & \multicolumn{2}{|c|}{$\begin{array}{l}\text { Ovocytes } \\
\text { pénétrés }\end{array}$} & \multicolumn{2}{|c|}{ Nbre moyen spermatozoïdes } \\
\hline & & & & Nbre & $\%$ & Nbre & $\%$ & m. pellucide & pellucide \\
\hline 25 à $31 \mathrm{mn} .$. & 9 & 9 & 55 & 40 & 72 & 45 & 82 & 19,5 & 3,2 \\
\hline 35 a $46 \mathrm{mn} .$. & 11 & 10 & 68 & 46 & 68 & 51 & 75 & 18 & 5,5 \\
\hline 59 à $73 \mathrm{mn} .$. & 11 & 10 & 58 & 35 & 60 & 45 & 77,5 & 13 & 3,7 \\
\hline 86 à $117 \mathrm{mn}$. & 13 & 13 & 52 & $3{ }^{\prime}$ & 65 & 37 & 71 & 12 & 5,6 \\
\hline 140 à $157 \mathrm{mn}$. & 7 & 6 & 56 & 36 & $6^{\prime}$ & 42 & 75 & 24 & 3,0 \\
\hline
\end{tabular}


que si le pourcentage des œufs pénétrés est voisin de $75 \mathrm{p}$. Ioo, la durée de lavage n'a aucune influence sur ce pourcentage.

\section{b) Comparaison avec et sans lavage préalable.} l'œuf?

Ceci remettait-il en cause l'existence d'une substance répulsive diffusante de

Il ne semblait pas, puisque seule la rotation discontinue, c'est-à-dire un lavage, pendant que les gamètes étaient en présence, autorisait à passer de r3,2 p. roo de fécondation (tubes de culture immobiles) à plus de $65 \mathrm{p}$. Ioo.

Nous en avons eu confirmation par les deux expériences suivantes ('Tableau 5).

I. - Étude des pourcentages de fécondation sans lavage mais après des temps de mise en contact des gamètes allant de 7 heures à 2 heures 30 .

2. - Comparaison des pourcentages de fécondation avec ou sans lavage préalable pour le temps le plus court de mise en contact des gamètes, soit 2 heures 30 .

Le tableau 5 résume les résultats. I1 montre que sans lavage préalable le pourcentage de fécondation qui s'élevait à 66 p. Ioo (8I p. Ioo de pénétrés ) après 4 heures à 7 heures de culture, tombe à 40,4 p. Ioo (50 p. Ioo de pénétrés) quand la durée de mise en contact des gamètes s'abaisse à 3 heures environ et à 28 p. IOO (35 p. Ioo de pénétrés) quand la durée de culture n'est plus que de 2 heures 30 .

TABLEAU 5

\begin{tabular}{|c|c|c|c|c|c|c|c|c|c|c|}
\hline \multirow{2}{*}{$\begin{array}{l}\text { Nombre } \\
\text { Lapines } \\
\text { (Pontes) }\end{array}$} & \multirow{2}{*}{$\begin{array}{l}\text { Pontes } \\
\text { fécondées }\end{array}$} & \multirow{2}{*}{$\begin{array}{l}\text { Nbre } \\
\text { total } \\
\text { œufs }\end{array}$} & \multicolumn{2}{|c|}{$\begin{array}{c}\text { œufs } \\
\text { fécondés }\end{array}$} & \multicolumn{2}{|c|}{$\begin{array}{c}\text { œufs } \\
\text { pénétrés }\end{array}$} & \multicolumn{2}{|c|}{$\begin{array}{c}\text { Nombre } \\
\text { spermatozoïdes }\end{array}$} & \multirow{2}{*}{$\begin{array}{l}\text { Durée } \\
\text { culture }\end{array}$} & \multirow{2}{*}{ Lavage } \\
\hline & & & Nbre & $\%$ & Nbre & $\%$ & sur ou dans & sous & & \\
\hline 7 & 7 & 46 & 35 & $76 \%$ & 41 & $89 \%$ & 9 & 3 & $6 \mathrm{~h} 59$ à $7 \mathrm{~h} 12$ & Non \\
\hline $7 \ldots$ & 7 & 59 & 34 & $58 \%$ & 42 & $71 \%$ & 16,5 & 1,2 & $5 \mathrm{~h} 55$ à $6 \mathrm{~h} 03$ & Non \\
\hline $12 \ldots$ & 12 & 75 & 52 & $69 \%$ & 61 & $83 \%$ & 16 & 3 & $4 h 53$ à 5 h 12 & Non \\
\hline $8 \ldots \ldots$ & 8 & 63 & 41 & $65 \%$ & 54 & $86 \%$ & 13,5 & 3 & $3 \mathrm{~h} 58$ à lht 2 & Non \\
\hline $8 \ldots$ & 5 & 42 & 17 & $40 \%$ & 21 & $50 \%$ & 6 & 2,5 & $2 \mathrm{~h} 58$ à $3 \mathrm{~h} 10$ & Non \\
\hline $16 \ldots$ & 9 & 109 & 31 & $28 \%$ & 38 & $35 \%$ & 6 & 0,7 & $2 \mathrm{~h} 1 \mathrm{~s}$ à $2 \mathrm{~h} 36$ & Non \\
\hline $10 \ldots$ & 9 & 67 & 42 & $63 \%$ & 46 & $69 \%$ & 12,1 & 0,9 & $2 \mathrm{~h} 28$ à $2 \mathrm{~h} 36$ & $\mid \begin{array}{ll}\text { Oui } \\
1 & \text { heure }\end{array}$ \\
\hline
\end{tabular}

Au contraire, si un lavage préalable d'une heure est pratiqué, après 2 heures 30 de culture le pourcentage remonte à $63 \mathrm{p}$. Ioo (69 p. Ioo de pénétrés).

De plus, les œufs fécondés après 2 heures 30 sans lavage préalable, sont aux tous premiers stades de la fécondation; après 2 heures 30 avec lavage préalable, au contraire, les pronucléi sont déjà formés. Ainsi quand on place les ovocytes avec les spermatozoïdes sans lavage préalable, la pénétration ne se produit qu'après deux à trois heures. Ce délai doit être considéré en fait comme le temps de lavage. Ce délai est supprimé quand le lavage a lieu séparément.

$6^{\circ}$ Rôle des secrétions des voies génitales femelles.

Ceci nous a conduit à rechercher s'il existait dans la trompe une substance qui viendrait neutraliser la substance spermo-répulsive émise par l'œuf puisque si 
au moment de la fécondation, les spermatozoïdes sont rares au voisinage de l'ovocyte, la fécondation a lieu in vivo dès l'ovulation.

Nous avons effectué trois séries d'expériences.

Io Prélèvement in vivo des spermatozoïdes :

A des ovocytes placés dans les petits tubes aussitôt après la collecte, on ajoute des spermatozoïdes prélevés in vivo sur une lapine anesthésiée ( $\mathrm{L}_{\text {. }}$ N.), comme il a été indiqué.

Dans ces conditions, les résultats sont très supérieurs à ceux obtenus dans les mêmes conditions avec du sperme recueilli par perfusion aussitôt après abattage (moyenne de référence).

8 pontes sur II ont été fécondées $\quad: 72 \mathrm{p}$. IoO

28 œufs sur $9 \mathrm{I}$ étaient fécondés $\quad: 30 \mathrm{p}$. Ioo.

40 œufs étaient soit fécondés soit pénétrés : $44 \mathrm{p}$. Ioo.

(Dauzier et 'Thibaulit, I959).

$2^{\circ}$ Fécondation in vitro dans des trompes (ampoule) en survie dans du Locke oxygéné :

A des trompes contenant des ovocytes vierges on ajoutait des spermatozoïdes recueillis par perfusion après abattage : les extrémités des trompes étaient ou non ligaturées.

Nos résultats portés sur le tableau 6 montrent une fécondité semblable à celle obtenue dans les petits tubes (moyenne de référence).

$3^{\circ}$ Fécondation in vitro dans des trompes (ampoule) maintenues en survie dans du Locke sans oxygène:

En répétant la même expérience mais sans aucune oxygénation du milieu nous n'avons obtenu aucune fécondation,

TABLEAU 6

Insémination in vitro dans les trompes.

\begin{tabular}{|c|c|c|c|c|c|c|c|}
\hline \multirow{3}{*}{ Techniques } & \multirow{3}{*}{$\begin{array}{c}\text { Nombre } \\
\text { de } \\
\text { pontes }\end{array}$} & \multirow{3}{*}{$\begin{array}{c}\text { Nombre } \\
\text { fécondation }\end{array}$} & \multicolumn{5}{|c|}{ Ovocytes } \\
\hline & & & \multirow{2}{*}{$\begin{array}{l}\text { Nombre } \\
\text { total }\end{array}$} & \multicolumn{2}{|c|}{ Fécondés } & \multicolumn{2}{|c|}{ Fécondés et pénétrés } \\
\hline & & & & Nombre & $\%$ & Nombre & $\%$ \\
\hline \multicolumn{8}{|l|}{$\begin{array}{l}\text { Trompes avec ovo- } \\
\text { cytes vierges en } \\
\text { survie dans: }\end{array}$} \\
\hline $\begin{array}{l}\text { Locke oxygéné .... } \\
\text { Locke non oxygéné. }\end{array}$ & $\begin{array}{r}43 \\
7\end{array}$ & $\begin{array}{r}13 \\
0\end{array}$ & $\begin{array}{r}219 \\
44\end{array}$ & $\begin{array}{r}31 \\
0\end{array}$ & $\begin{array}{c}14,1 \\
0\end{array}$ & $\begin{array}{r}40 \\
0\end{array}$ & $\begin{array}{c}18,2 \\
0\end{array}$ \\
\hline Témoins in vivo ... & 20 & 17 & $10 x^{\prime}$ & 84 & 83 & & \\
\hline
\end{tabular}

La valeur des gamètes utilisées dans ces trois séries d'expériences a été contrôlée en répétant exactement les mêmes opérations, mais in vivo, dans des trompes de 
Lapines anesthésiées. Comme le montre la dernière ligne du tableau dans ce cas, le taux normal de fécondation naturelle fut presque atteint sans délai.

\section{B. - Brebis et Truie}

Le tableau 7 résume les résultats obtenus avec des ovocytes de Brebis et de Truie. On remarque que la fécondation ne se produit jamais avec du sperme frais, mais on constate qu'avec le sperme maturé, que les ovocytes soient lavés ou non, la fécondation ne se produit que très rarement chez la Brebis et chez la 'Truie. Les conditions qui permettent la fécondation sont donc différentes de celles de la Lapine et restent à découvrir.

TABLEAU 7

Fécondation In vitro

\begin{tabular}{|c|c|c|c|c|c|}
\hline & $\begin{array}{l}\text { Nombre total } \\
\text { d'œufs }\end{array}$ & $\begin{array}{l}\text { Lavage des } \\
\text { œufs }\end{array}$ & Nature du sperme & $\begin{array}{l}\text { Milieu de } \\
\text { culture }\end{array}$ & $\begin{array}{l}\text { Nombre d'œufs } \\
\text { fécondés }\end{array}$ \\
\hline \multirow{3}{*}{ Brebis........ } & 41 & néant & frais & Locke-serum & 0 \\
\hline & 51 & néant & $\begin{array}{l}\text { maturé } \\
\text { (11 à } 24 \text { heures) }\end{array}$ & Locke & 3 \\
\hline & 5 & 1 heure & $\begin{array}{c}\text { maturé } \\
\text { (13 heures) }\end{array}$ & Locke & 0 \\
\hline \multirow{3}{*}{ Truie. } & 31 & néant & frais & Locke & 0 \\
\hline & 13 & néant & $\begin{array}{l}\text { maturé } \\
\text { (7 heures) }\end{array}$ & Locke & 1 \\
\hline & 43 & 2 à 2 heures 30 & $\begin{array}{l}\text { maturé } \\
\text { (7 heures) }\end{array}$ & Loéke & 0 \\
\hline
\end{tabular}

\section{DISCUSSION}

Ces expériences ne nous permettent pas encore d'aboutir à utn schéma absolument précis de la pénétration du gamète mâle chez les Mammifères, mais elles apportent assez d'éléments nouveaux pour pouvoir dessiner les grandes lignes chez la Lapine.

Le spermatozoïde subit dans les voies génitales femelles sa maturation. Cette maturation le rend apte à traverser la membrane pellucide, mais inversement, le sensibilise à 1'action spermo-répulsive de la substance émise par l'ovocyte alors que le sperme non maturé peut se coller sur la pellucide mais ne peut la franchir.

In vitro, cette substance peut être éliminée par lavages répétés, l'œuf devient alors accessible au sp=rmatozoïde maturé qui digère la pellucide devant lui et peut ainsi atteindre le cytoplasme.

Cependant quand la fécondation s'effectue dans les tubes en rotation, la substance émise par les œufs n'est pas éliminée, puisqu'il n'y a pas de changement de liquide, ceci suppose que la substance n'a pas une action spermo-inhibitrice mais simplement spermo-répulsive à une certaine concentration, car dans les microtubes la répulsion reste totale.

In vivo, semble exister une autre substance qui est capable de neutraliser celle émise par l'œuf puisque chez la Lapine la fécondation se produit dès l'ovulation. 
L'agitation continuelle dont l'œuf est l'objet dans les trompes facilite à la fois l'élimination de la substance ovocytaire et sa neutralisation par la substance femelle (WINTENBERGER-TORRÈs, Ig6I).

La substance femelle parait être sensible à l'absence d'oxygène, c'est pourquoi elle ne peut être mise en évidence qu'en prélevant le liquide utéro-tubaire sur l'animal vivant et en opérant très vite. Ceci contredit l'hypothèse de MoRICARD sur la nécessité d'une faible tension en oxygène pour que se produise la fécondation.

Dans ce schéma, établi d'après des faits expérimentaux solides, quelques liaisons restent difficiles à établir. On doit en particulier se demander si la maturation des spermatozoïdes fait appel aux mêmes substances secrétées par les voies génitales femelles que celles qui assurent la neutralisation de la substance spermo-répulsive de l'ovocyte. Nous ne le pensons pas, car la maturation des spermatozoïdes est une réaction très lente et non une réaction du type antigénique ; cependant, on peut " dématurer " instantanément le spermatozoïde de Lapin en le plaçant dans du plasma séminal (ChANG, I959) ou en le suspendant dans un milieu contenant $25 \mathrm{p}$. Ioo de jaune d'œuf (Dauziér et Thibauli non publié, 44 ovocytes de 6 lapines, aucun n'est fécondé). Dans ce dernier cas la " dématuration " est complète avec indifférence recouvrée à l'égard de la substance spermo-répulsive puisque des spermatozoïdes maturés, perfusés avec du jaune d'œuf-citrate, se collent à la pellucide comme des spermatozoïdes fraîchement éjaculés, mais ne peuvent la traverser.

Les analogies de ces réactions avec celles existant dans différentes espèces, en particulier l'Astérie et l'Oursin, entre l'œuf et le spermatozoïde sont évidentes, mais la présence de la sécrétion génitale femelle complique la question; on peut se demander si la substance émise par l'ovocyte et celle émise par la trompe ont le droit d'être homologuées respectivement à une "fertilisine " et à une "antifertilisine "? Nous admettrons provisoirement une certaine analogie.

Remarquons que l'analogie avec les Invertébrés va plus loin, car nous avons pu mettre également en évidence une lysine (fig. 7 et 8) sans qu'il nous soit possible de dire si elle provient du spermatozoïde seul.

On remarque en effet que des œufs mis en présence de spermatozoïdes maturés, mais placés dans des conditions telles (micro-tubes par exemple) que les spermatozoïdes ne puissent les féconder par suite de la concentration élevée de "fertilisine", sont en quelques heures l'objet d'une cytolyse profonde, alors que des œufs vierges cultivés dans des conditions identiques, sans spermatozoïdes, se conservent sans trace de cytolyse pendant plus de six heures. Nous admettrons donc qu'il existe également une spermo-lysine.

Ces résultats sont propres à la Lapine car malgré l'intérêt d'une généralisation à d'autres Mammifères, les études en cours chez la Brebis et la Truie ne nous ont pas permis de confirmer ces résultats.

Reçu en janvier 1961.

\section{SUMMARY}

\section{FERTILIZATION STUDIES OF RABBIT OVA IN VITRO.}

In this work 1954 Rabbit does and 7605 virgin oocytes were used. The oocytes were recovered I I-I 2 hours after mating with a vasectomized buck.

In almost all the experiments, the eggs were fixed in Bouin fluid, 2 to 7 hours after the in vitro insemination, embedded in agar paraffin and serial sections examined. 

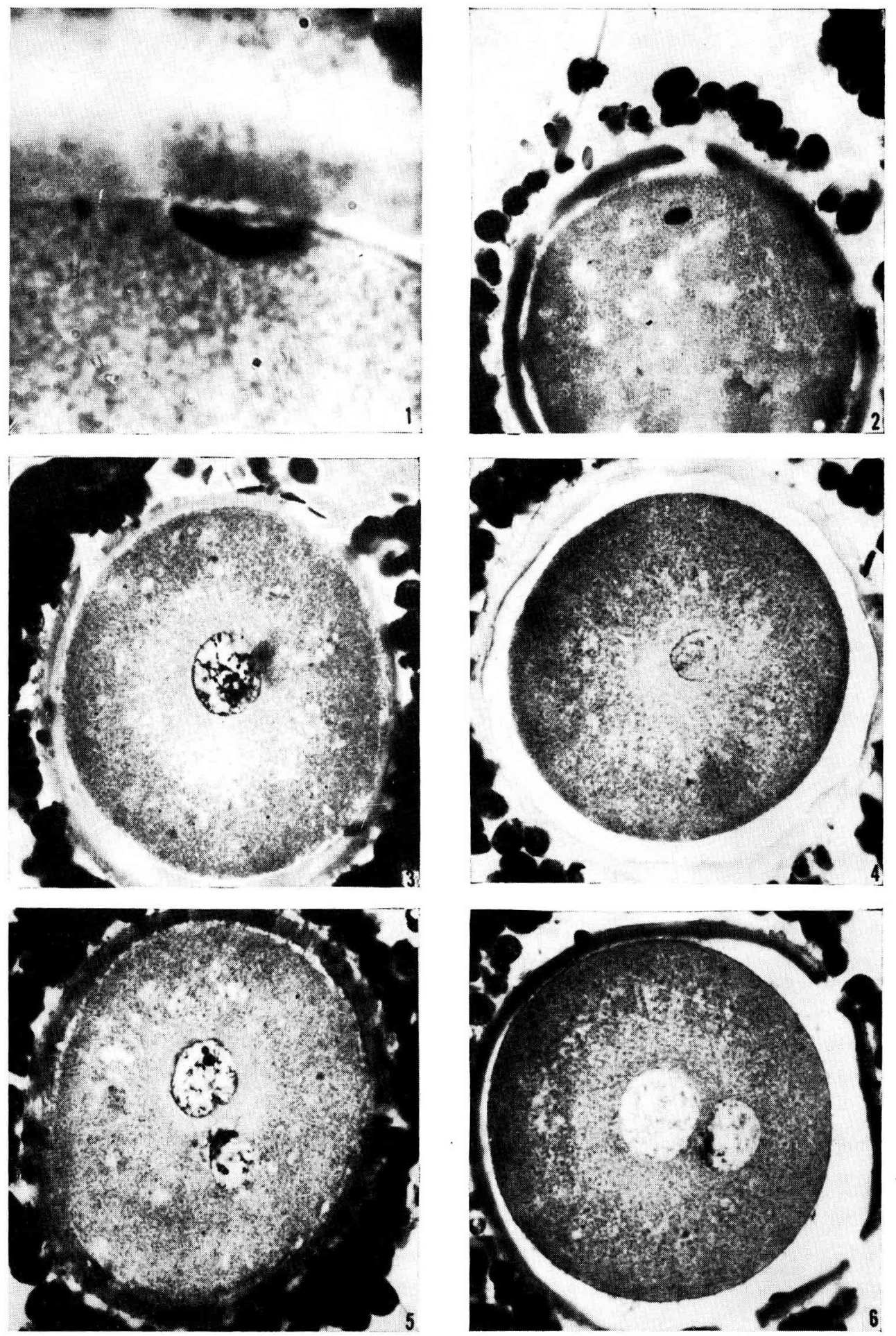

PLANCIIE I

FIc. I. - Pénélration du spermalozoide fécondant dans le cytoplasme. Renarques le gonflement immédiat : dés la pénétration l'aspect foliacé de la tête disparaît. -- FlG. 2. - Ovocyte non fécondé montrant un "artefact "lypique : tête de spermatosoide entrainée par le rasoir et semblant êlre dans le cyloplasme. -

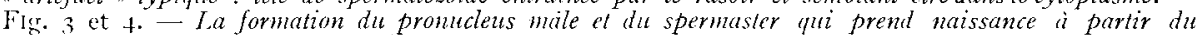
centrosome de la pièce intermédiaire. - FIG. 5. - Les pronucléi mále el femelle. Le pronucleus mále est ì un stale plus avancé. I.e pronucleus fentle se forme. - Fig. 6. -- Quand les pronucléi mâle et femelle sont subscentraux et pleinement formés, le pronucleus femelle est plus petit et toulours reconnaissable par suite de la polarisation de sa chromatine ters le pronucleus mále. 

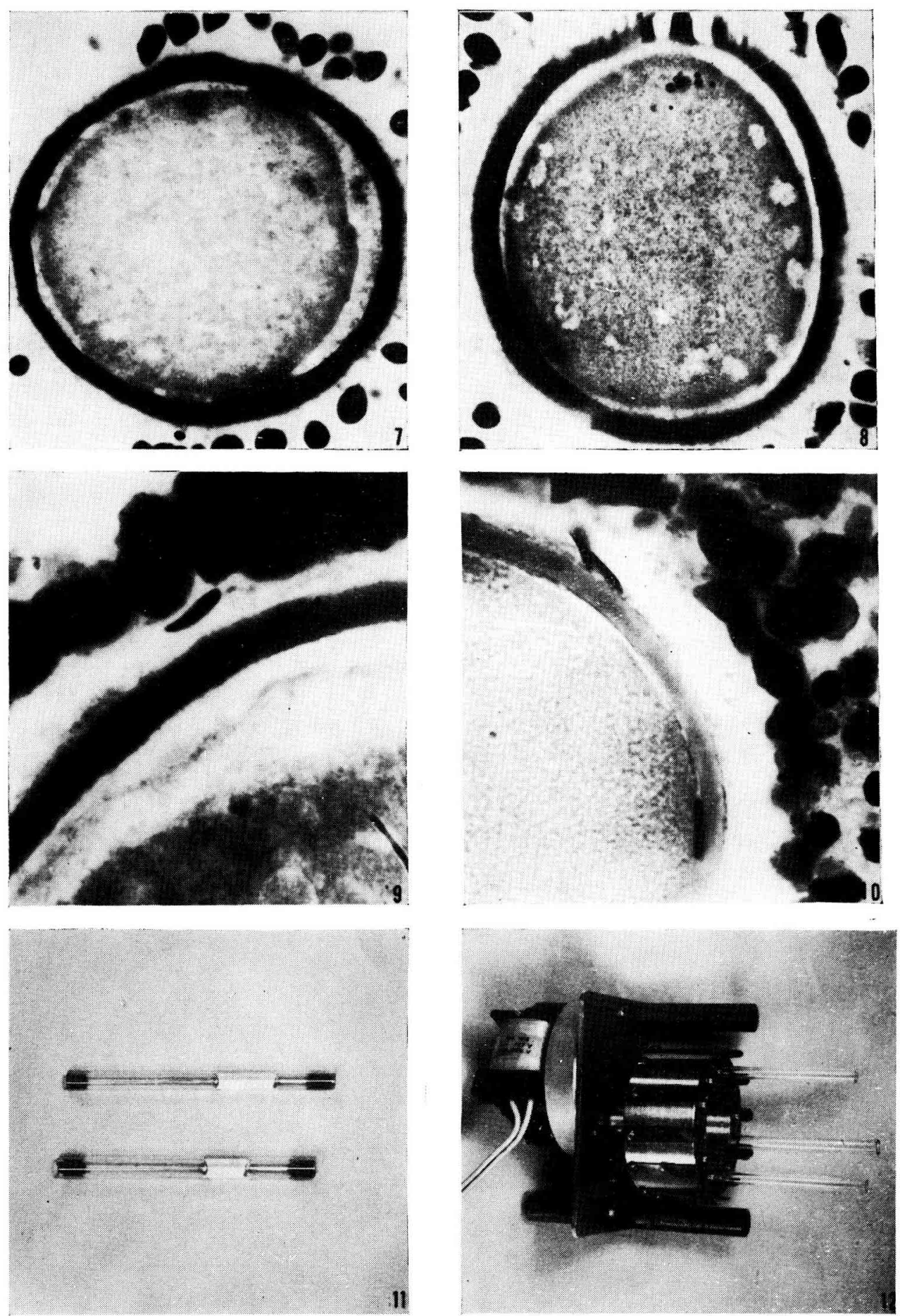

\section{Planche 2}

FIg. 7 et 8. - Ovocyles cullivés pendant 4 heures dans un "microtube "en présence de spermatozol̈des maturés. Remarquez : - la démolition complète de la corona radiata, bien qu'aucun spermatozoïde ne soit demeuré au voisinage des ovocytes. - Les phénomènes de cytolyse très évidents. -- Fig. 9. Exemple d'un spermalozoide n'atteignant pas la membrane pellucide d'un ovocyte non lavé. FIG. ro. - Deux spermatozoïdes collés sur la pellicule d'un a'uf lavé et fécondé in vitro. Remarquez également le spermatosoide présent sous le membrane pellucide. - FIG. I . - "Petil tube "en haul et "gros tube" en dessous montrant la disposition du milieu de culture au centre. - FIG. I2. - Appareil utilisé pour le lavage des ovocytes. Le porle-tube contient "zn "gros tube " et deux "petits tubes". Le moteur électrique est relié à un chronolron qui assure la rotation du porte-tube d'un tonr et deni toutes les 35 secondes. Ce chronotron ne figure pas sur la photographie. 
The presence either of a swelling sperm head and mid-piece with or without an aster formation and the second polar body, or of male and female pronuclei, was used as the criterion of fertilization.

The mixing in a small glass tube containing Locke medium of the oocytes and spermatoza, recovered from the uterine horn of a Rabbit doe mated i 2 hours previously with a normal buck, resulted in the fertilization of 12 I out of 922 eggs (I3, I p. Ioo).

In the oocyte there is a fertilizine-like substance which diffuses from and around the oocyte and prevents the capacited sperm from sticking to the zona pellucida.

In order to be certain of obtaining fertilization in vitro the dispersal of "fertilisine "from the region of the zona pellucida and its liberation into the medium must be provoked. This operation takes about two hours and the penetration of the spermatozoa begins immediately afterwards Out of 532 oocytes thus treated, 353 were fertilized, that is $66 \mathrm{p}$. I00, and $4 \mathrm{I} 8$ were fertilized or penetrated (having at least one spermatozoa under the zona pellucida), that is $78,5 \mathrm{p}$. 100; the eggs were fixed 4 to 7 hours after the spermatozoon were placed in contact with the oocytes.

Other experiments reported here indicate that, in vivo, an antifertilizine-like substance is produced by the female tract. This substance, very sensitive to the lack of oxygen, neutralizes the fertilizine-like substance and leaves the way clear for the sperm to stick and to penetrate the zona pellucida.

From the spermatozoa diffuses also a lysin which produces cytolysis of unwashed virgin oocyte cultured in capacitated sperm suspension of very small volume $(0, \mathrm{rml})$, situation which pratically prevents fertilization ( 8 p. Ioo).

In rabbit sperm penetration cannot occur in vitro before the "fertilizin-like " substance is partially removed. Since we did not succeed in fertilizing ewe-egg and sow-egg in vitro, this conclusion may not be valid for all species of Mammals.

\section{RÉFÉRENCES BIBLIOGRAPHIQUES}

Austin C. R., Bishor M. W. H., I957. Fertilization in mammals. Biol. Rev., 32, 296-349.

AUSTIN C. R., BRADEN A. W. H., I954. Time relations and their significance in the ovulation and penetration of eggs in rats and rabbits. Aust. J. Biol. Sci., 7, 179-194.

Chang M.C., r95I. Fertilizing capacity of spermatoza deposited into the fallopian tubes. Nature 168, 697698.

Chang M. C., 1959. Fertilization of rabbit ova in viro. Nature, 184, suppl. 7, 466.

Chang M. C., I959. Fertilizing capacity of spermatoza. Recent progress Endocrinol. Reproduc., Syracuse, I $32-16_{5}$.

DaUZIER L., ThiBault C., 1956. Recherche expérimentale sur la maturation des gamètes mâles chez les mammifères par l'étude de la fécondation in vitro de l'œuf de Lapine. Proc. IIId internat. Cong. Anim. Reprod. Cambridge.

Dauzier L., Thibault C., 1959. Données nouvelles sur la fécondation in vitro de l'œuf de la lapine et de de la brebis. C. R. acad. Sci., 248, 2655-2656.

Frommolt G., I934. Die Befruchtung und Furchung der Kanincheneies im Film. Zbl. Gynäk, 58, 7-I2.

KRASOVSKaYA O. V., I935. Cytological study ot the heterogeneous fertilization of the egg of rabbit outside the organism. Acta Zool., 16, 449-59.

LONG J.A., I9I 2 . The living eggs of rats and mice with a description of an apparatus for obtaining and observing them. Mémoirs. Univ. Calif. Publ. Zool., 9, ro5-36.

MeNkin M. F., Rock J., I948. in vitro fertilization and cleavage of human ovarian eggs. Amer. J. Obstet. Gynec., 55, 440-52.

MORICARD R., r949. Penetration in vitro du spermatozoïde dans l'ovule des mammifères et niveau du potentiel d'oxydo-réduction tubaire. C. R. Soc. Franc. Gyn., $19{ }^{\mathrm{e}}$ année, 8, 226.

MoRICARD R., I950.a. Premières observations de la pénétration du spermatozoïde dans la membrane pellucide d'ovocytes de Lapines fécondés in vitro, niveau de potentiel d'oxydo-réduction de la sécrétion tubaire. C. R. Ass. Inat., $37^{\circ}$ réunion, $337-349$.

MORICARD R., I950.b. Pénétration of the spermatozoa in vitro into the mammalian ovum, oxydo potential level. Nature, 165, 763 .

MORICARD R., I954. Étude cinématographique de la fécondation réussie in vitro de l'ovule de Lapine. Bull. Fed. Soc. Gynec. Obst., 6, $27 \mathrm{I}-275$.

MORICARD R., I955. La fonction fertilisatrice des sécrétions uéro-tubaires (Etude microcinématographique de la fécondation in vitro de l'ovocyte de Lapine). in La fonction tubaire et ses troubles, I vol. Masson, Paris.

Onanoff J., I893. Recherches sur la fécondation et la gestation des mammifères. C. R. Soc. Biol., 45, 719.

ORTavant R., Thibault C., Wintenberger S., I949. Contributions à l'étude de la superovulation expérimentale chez la Brebis. Ann. Endocr., 10, I $70-173$.

Petrov G. N., r958. Fécondation et phases primaires de division de l'œuf humain hors de l'organisme. Arch. Anal., 35, (I), 88-9г.

Pincus G., I930. Observation of the living eggs of the rabbit. Proc, Roy. Soc. B., 107, 132-67.

PrNcus G., r93\%. The comparative behaviour of mammalian eggs in vivo and in vitro-IV. the development of fertilized and artificially activated rabbit eggs. J. Exp. Zool., 82, 85-I 29.

Pincus G., Enzmann E. V., I932. Fertilization in the rabbit. J.Exp. Biol., 9, 403-8.

Annales de Biologie Animale. - ig6r. 
Pincus G., Enzmann E. V., 1934. Can mammalian eggs undergo normal development "in vitro". Proc. Nat. Acad. Sci. Wash., 20, 12 I-2.

Pincus G., EnzmanN E. V., I935. The comparative behaviour of mammalian eggs in rivo and in ritro. J. Exp. Med., 62, 665-75.

PINCUS G. ENZMANN E. V., I936. The comparative behaviour of mammalian eggs in vivo and in vitro. II. The activation ot tubal eggs of the rabbit. J. Exp. Zool., 73, I95-208.

Pincus G., SHapIRo H., 1940. Further studies on the parthenogenetic activation of rabtiv rggs. Proc. Nat. Acad. Sci. Wash., 26, 163-5.

Rock J., Menkin M. F., I944. In vitro fertilization and cleavage of human ovarian eggs. Science, 100, I05.

SHENK, r880. Das Saügethierei Künstlich befrüchtet ausserhalb der Mutterthierei. Mitl. Embryol. Inst. Wien., 1, ro7.

SHETTLES I. E., 1953. Observation on human tubal and follicular ova. Amer. J. Obstet. Gynec., 66, $235-47$.

ShetTles L. B., I955. A morula stage of Human ovum developed in vitro. Fertil. Steril., 6, 287-289.

SmitH A. U., r951. Fertilization in vitro of the mammalian egg. Biochem Soc. Symp., no 7, 3-ro.

Thibault C., I949. L'ouf des mammifères. Son développement parthénogénétique. Ann. Sci. Nat. Zool., 11, $136-219$.

Thibault C., 1959. Analyse de la fécondation de l'ouf de la truie après accouplement ou insémination artificielle. Coll. Reprod. Insém. Art. Jouy-en-Josas, Ann. Zoot., suppl. I959, I65-1 77.

Thibault C., I962. Analyse comparée de la fécondation chez la Lapine, la Brebis, la Vache, la Truie. Ann. Biol. anim. Bioch. Biophys., 2, (à paraître).

Thibault C., Dauzier L., rg60. "Fertilisines" et fécondation in vitro de l'œuf de la Lapine. C. R. Acad. Sci. 250, I $358-1359$.

Thibault C., Dauzier L., Wintenberger S., i954. La fécondation in vitro de l'œuf de la Lapine. $C . R$. Soc. Biol, , 148, 789 .

Wintenberger-Torres S., ig6r. Motilité des trompes et progression des oufs chez la Brebis. Ann. Biol. anim. Bioch. Biophys., 1, 121-123. 